\title{
DURABILITY OF PELLETS OBTAINED FROM ENERGY PLANTS: REVIEW
}

\author{
Bianca-Stefania Zabava, Gheorghe Voicu, Mirela-Nicoleta Dinca, Nicoleta Ungureanu, Mariana Ferdes \\ University Politehnica of Bucharest, Romania \\ bianca.dragoiu@yahoo.com,ghvoicu_2005@yahoo.com,mirela_dilea@yahoo.com, \\ nicoletaung@yahoo.com, marianaferdes@yahoo.com
}

\begin{abstract}
The interest in bioenergy, as a renewable energy source, has increased tremendously in the recent years. Biomass is a renewable source of energy that has an important contribution in reducing the use of conventional fuels and in reducing greenhouse gas emissions to the atmosphere. In this context, an increasing attention is given to the production and use of environmentally friendly biofuels: pellets and briquettes, biogas, biodiesel and bioethanol. Pelleting and briquetting processes have been used for many years to produce densified biomass for fuel applications. Densified biomass fuels such as pellets are preferred as they provide better economic viability for transport, storage and handling. The aim of this review is to examine the main factors that influence the durability of the pellets, (such as: biomass characteristics, moisture content, size reduction, and also the pelleting conditions, including the use of binders, feedstock mixes and operating temperature), because the durability is considered a measure of the quality of the pellets. Pellet durability can also be affected by the storage conditions. The mechanical durability of pellets is the measure of the resistance of densified fuels towards shocks or abrasion in consequence of transport and handling processes. In the paper there are analyzed all the parameters mentioned above for the pellets produced from different types of biomass (cereal residues, wood chips and energy crops), highlighting the influence of each on the process and their sustainability.
\end{abstract}

Keywords: biomass, durability, pellets, energy plants.

\section{Introduction}

Interest in renewable energy resources has increased in recent years because of the rising energy demand and fuel costs, environmental and national security concerns and finite supplies of fossil fuels. As power generators continue their search for alternative energy sources to coal, biomass remains a promising carbon-based renewable fuel [1]. Biomass is a renewable source of energy that has an important contribution in reducing the use of conventional fuels and in reducing greenhouse gas emissions to the atmosphere. In this context, an increasing attention is given to the production and use of environmentally friendly biofuels: pellets and briquettes, biogas, biodiesel and bioethanol. Biomass is the totality of organic substances occurring in a natural habitat, a distinction being made between phytological and zoological mass [2]. Biomass pellets (wood, wheat straw, rape straw, and peat) as fuels are of great interest for district heating because they can contribute to greenhouse gas emission reductions and provide a more efficient use of local energy resources [3]. Pellets are a suitable biomass feedstock for both heat and power applications, with co-firing in coal-fired power stations currently being their main large-scale application. The industrial trade for wood pellets involves the international bulk transport of more than 10 million tons annually.

Production of pellets and the demand have been rapidly increased in Canada, America, Europe, and China in the past few years. It is estimated that the demand for pellets will be tripled from 2012 to 2020, rising from 16 million to 46 million metric tons per year [4]. As one of the main pellet producers, the Canadian pellet industry is looking for alternative sources of feedstock.

The impact of thermal treatment on the properties of pellets has also been investigated $[5 ; 6]$ with a reduction of moisture uptake reported with increasing severity of thermal treatment. Peng et al. [5] manufactured pellets from sawdust samples torrefied at a temperature range of 240 to $340{ }^{\circ} \mathrm{C}$ and compacted at a range of temperatures and pressures, whilst Lamet al. [6] investigated the steam explosion of Douglas fir at four different treatment severities (at 200 and $220^{\circ} \mathrm{C}$ and for 5 and $10 \mathrm{~min}$ at each temperature).

The aim of this review is to examine the main factors that influence the durability of the pellets, because the durability is considered a measure of the pellet quality. Pellet durability can also be affected by the storage conditions. The mechanical durability of pellets is the measure of the resistance of densified fuels towards shocks or abrasion in consequence of transport and handling processes. In the paper there are analyzed all the parameters mentioned above for the pellets produced from different types of biomass (cereal residues, wood chips and energy crops), highlighting the influence of each on the process and their sustainability. 


\section{Materials and methods}

Biomass pelletizing process

The pelletizing process includes several steps that consist of raw material reception, drying, grinding, pelletization and cooling. Pellets are produced in a pellet mill that consists of a die with cylindrical press channels and rollers that force the feedstock to flow through the perforations to form pellets [7].

In practice, two categories of pellet presses are used: flat die pellet mill (Fig. $1 \mathrm{~b}$ ) and ring die pellet mill (Fig. 1 a) [8].
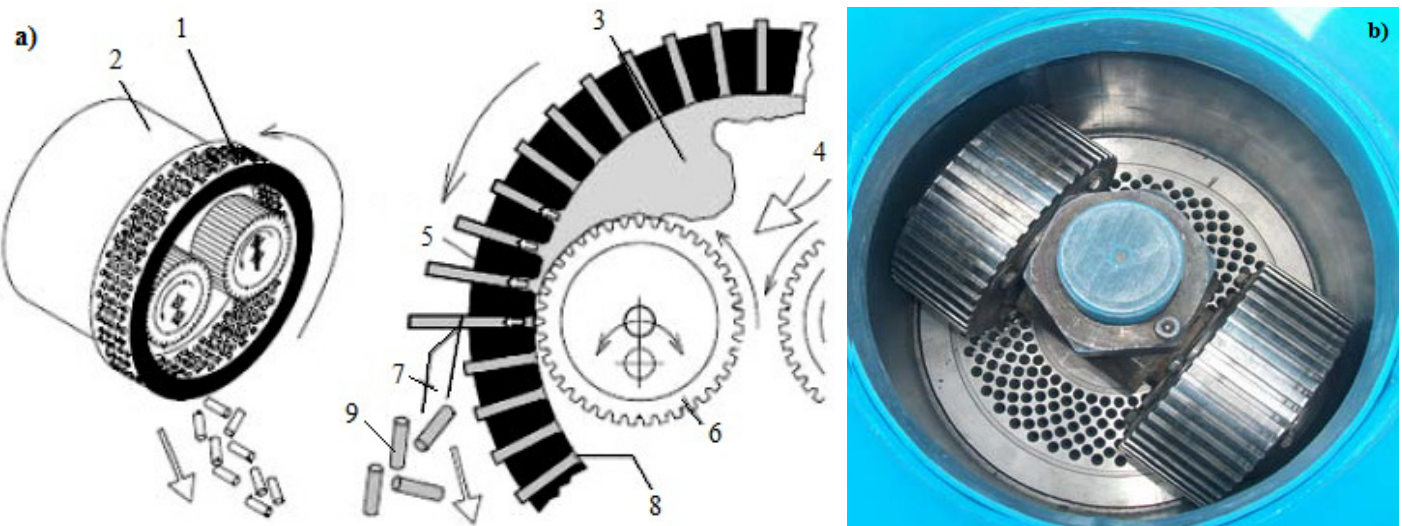

Fig. 1. Ring die pellet mill (a) and flat die pellet mill (b) [8]: 1 - ring die; 2 - gear; 3 - crushed material; 4 - material input; 5 - die; 6 - roller; 7 - cutter; 8 - pellet compressing hole; 9 - pellet

According to the new European pellets standard - EN 14961-1 [9], pellets for domestic use are 6$8 \mathrm{~mm}$ in diameter and the industrial ones are 10-12 $\mathrm{mm}$ in diameter with a length of 5-40 $\mathrm{mm}$.

The quality of fuel pellet is assessed based on its density and durability. The density, durability and specific energy consumption of the pelleting process are dependent on the pellet mill process variables (die diameter and die speed) and feedstock variables (moisture content, size reduction and composition) [10].

High density of pellets represents higher energy per unit volume of material, while durability is the resistance of pellets to resist various shear and impact forces applied during handling and transportation [11]. During the transportation and storage, the pellets with a lower mechanical durability are easily damaged; also, it will increase the powder content. Pellet durability should be in excess of $97.5 \%$, meaning that the pellets can withstand normal handling without falling apart [12].

\section{Results and discussion}

\section{Factors affecting biomass pellet durability}

In general, the pellet durability is determined by a few key parameters including the feedstock properties (moisture content, biomass particle size, feedstock chemical composition, addition of additives, biomass pre-treatment -steam explosion, microwave and radio frequency heating) and the process variables (die speed and diameter, cooling process) $[11 ; 13]$.

\section{Moisture content}

Water is a key parameter in the pelletizing process and, along with the lignin content, the moisture of the biomass determines the pellet durability. The optimum moisture content differs depending on the biomass feedstock used, such as: for pine it ranges between 6-13\%, straw 8-15\% and Miscanthus 20-25\% [14]. Găgeanu et al. [15] investigated the process of compacting wood biomass from Salix viminalis, in the form of pellets, following two of the parameters with the highest influence on the pelleting process: humidity and granulation of the feedstock. They concluded that the best pellets in terms of humidity, length, surface characteristics, calorific power and ash content were obtained for the particle size of about $3 \mathrm{~mm}$ and humidity of $9 \%$.

Miranda et. al. [16] studied the influence of the moisture content and bulk density on the durability of pellets obtained from 10 types of biomass: pyrenean oak (PO), pyrenean sylvestris (PS), 
cork powder (CP), pine sawdust (SW), vine shoots (VS), olive branches (OB), barley straw (BS), wheat straw (WS), olive pomace (OP) and grape pomace (GP).

Table 1

Properties of pellets from different biomass types [16]

\begin{tabular}{|c|c|c|c|c|c|c|c|c|c|c|}
\hline Property & PO & PS & CP & SW & VS & OB & BS & WS & OP & GP \\
\hline $\mathbf{M}, \boldsymbol{\%}$ & 6.35 & 9.5 & 8.02 & 9.3 & 10.8 & 6.5 & 7.2 & 9.4 & 6.86 & 7.05 \\
\hline BD, kg・m & 678 & 675 & 697 & 650 & 700 & 582 & 644 & 620 & 780 & 824 \\
\hline DU, \% & 95.41 & 97.2 & 96.79 & 98.2 & 98.8 & 97.5 & 95.5 & 94.4 & 91.41 & 85.83 \\
\hline
\end{tabular}

The highest durability was obtained for the moisture contents between $6.5-10.8 \%$. Pellets with very low moisture contents (OP and GP), had the lowest durability, probably due to insufficient agglomeration.

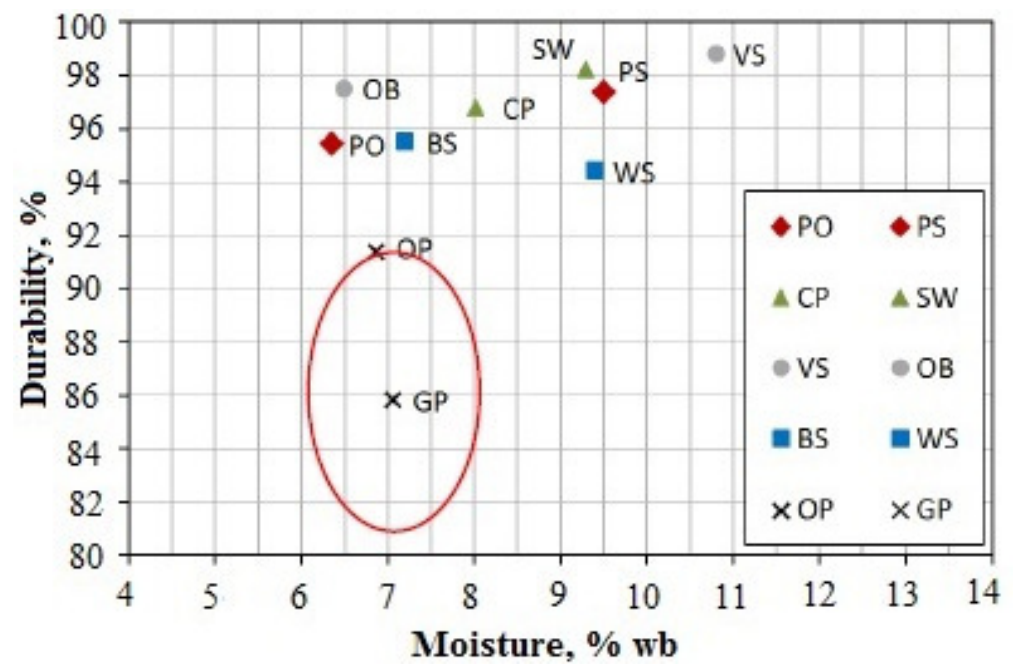

Fig. 2. Relationships between moisture and durability [16]

The bulk density of biomass makes it difficult to transport it over long distances and demands space for storage. Densification of biomass by pelleting can significantly increase the bulk density of biomass [13]. Miranda et. al. [16] reported that most pellets, with densities of $582-700 \mathrm{~kg} \cdot \mathrm{m}^{-3} \mathrm{had}$ high durability. The highest densities were obtained for agroindustrial wastes (OP and GP) showing the lowest durability.

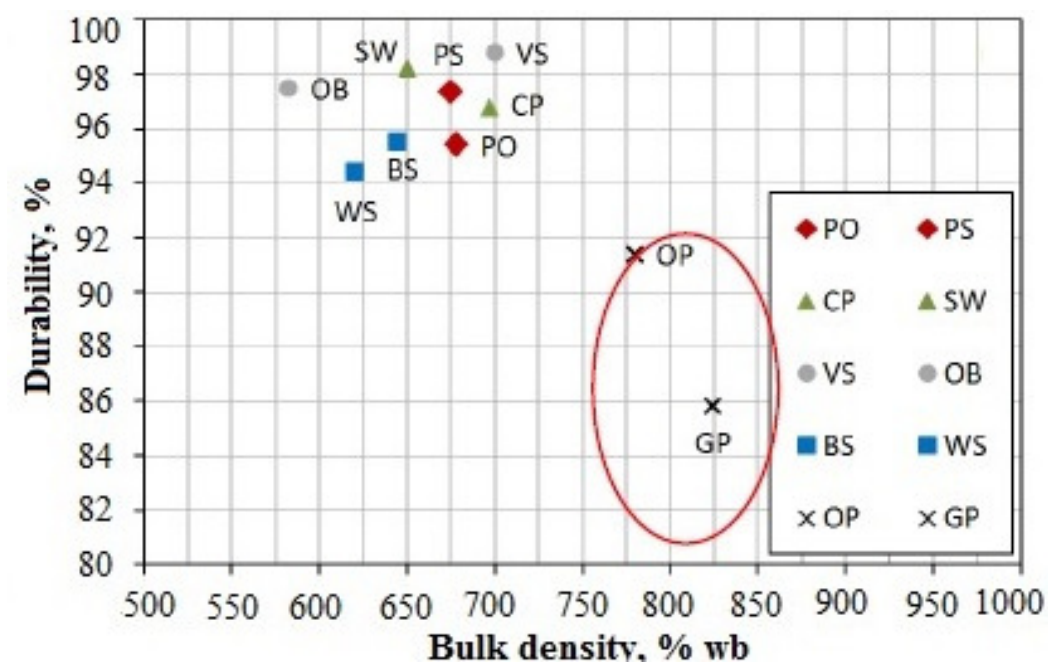

Fig. 3. Relationships between bulk density and durability [16]

Particle size

Feedstock size reduction, along with the moisture content, is one of the most important stages in the pelleting process. It can affect compaction, contact between particles, friction in the die and the 
flow rate of the material. Finer particle sizes generally correspond with greater pellet strength and durability as larger particles serve as fissure points. Size reduction is performed using a hammermill. For optimum durability it is recommended to use smaller screens sizes ranged between 0.5 and $8 \mathrm{~mm}$. On the other hand, a high content of fine particles can also lead to blockages [14; 17].

Fig. 4 shows the influence of the feedstock particle size on pellet durability. Cereal pellets showed a significant improvement in durability by reducing the screen size from 1.6 to $0.8 \mathrm{~mm}$ [18]. From this graph it can be seen that wheat gets the best value, of whatever particle size.

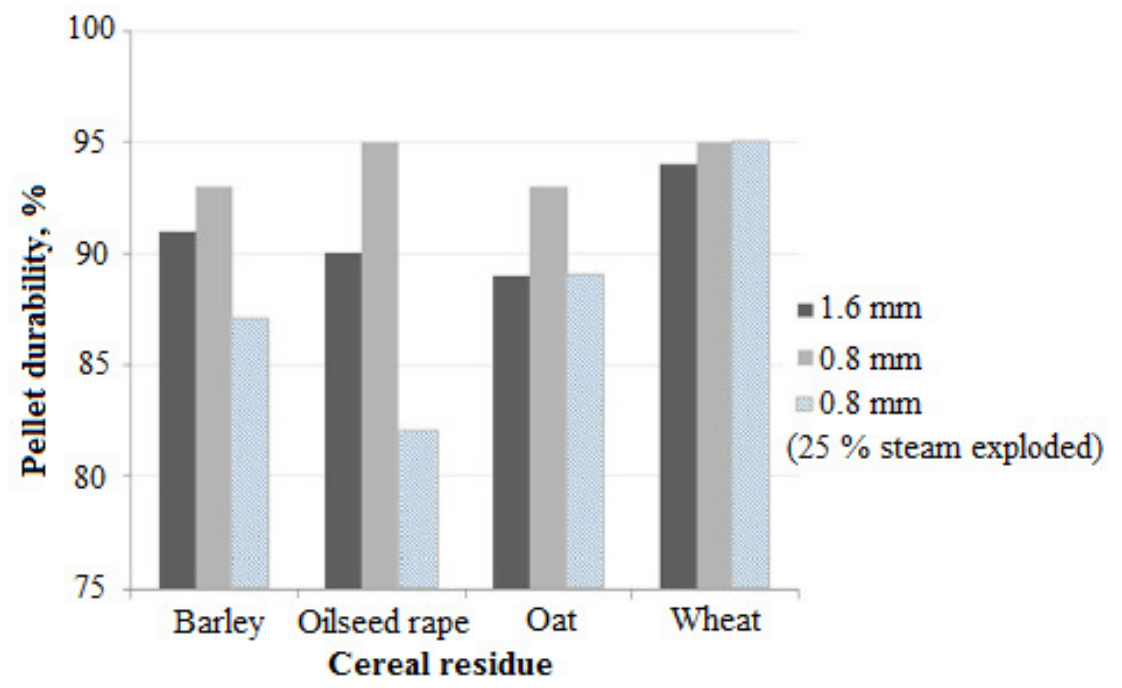

Fig. 4. Influence of particle size on different pellet durability [10]

Harun N.Y. and Afzal M.T. [19] investigated the influence of the particle size and blending on the mechanical properties of pellets made from agricultural biomass (reed canary grass, timothy hay and switchgrass) and woody biomass (spruce and pine) and their blends. The mechanical properties were evaluated for three different particle sizes: $150-300,300-425$ and 425-600 $\mu \mathrm{m}$. They reported that for all biomasses, pellets made from a lower particle size $(150-300 \mu \mathrm{m})$ exhibited higher density (950$1178 \mathrm{~kg} \cdot \mathrm{m}^{-3}$ for spruce and pine; $668-800 \mathrm{~kg} \cdot \mathrm{m}^{-3}$ for reed canary grass, timothy hay and switchgrass; $900-970 \mathrm{~kg} \cdot \mathrm{m}^{-3}$ for blended biomass).

\section{Feedstock chemical composition}

Feedstock composition contributes significantly to the quality of densified materials. Biomass chemical composition differs from species to species, and within the same species it depends on the age, location and habitat. Hemicellulose, cellulose, lignin and extractive matter are major constituents of biomass. Also, because of its organic nature, biomass contains carbon, oxygen, nitrogen and hydrogen [13]. There is a strong positive relationship between the pellet durability and lignin content. Lignin compositions vary between biomasses, and this affects the temperature, at which it plasticises, also known as the glass transition temperature. The temperature, at which a polymer softens and passes from a glassy into a plastic state, is called the glass transition temperature and is an important characteristic of polymers $[14 ; 20]$.

\section{The addition of additives}

Although many biomass feedstocks possess natural binders, they do not have enough strength due to the limitations of binding between particles. The most used additives are lignosulphonate, starch, dolomite, corn or potato flour, and some vegetable oils [21;22]. According to the European Pellet Council [23], additives are allowed to a maximum of $2 \%$ of the total mass of the pellets. Additives are added to improve the combustion properties, improve durability, or to reduce wear on the pellet die. Stahl M. et al [24] investigated in their article how white sugar, molasses and spent sulphite liquor additives affect the energy needed by the pellet press, the durability and oxidation of the produced pellets. They found that using sugar additive, the bulk density ( 7 to $15 \%$ ) and durability (10 to $20 \%$ ) of the pellets were increased.

Steam explosion uses high pressure steam to "activate" lignin for binding. This process produces significant physical, chemical, and structural changes in the biomass and makes lignin more available 
for binding during pelletization. For example, in willow, steam pre-treatment produced pellets with good strength and reduced ash content improved the combustion properties [14; 25].

Die speed and diameter

Die speed significantly affects the amount of the material that can be pelleted and the energy required for compression. This parameter can also influence the pellet durability by changing the retention time of material in the die. Tumuluru J.S., concluded that for the die speeds greater than $50 \mathrm{~Hz}$, corn stover moisture content of 33-34\% (w.b.) and preheating temperatures of $70{ }^{\circ} \mathrm{C}$ high durable pellets were obtained [26].

In their research, regarding the pelleted wheat distiller's dried grains with soluble, Tumuluru et al [27] reported that both the die diameter and steam addition had a significant effect on the bulk density and durability values of pellets. The highest bulk density and durability were achieved with $6.4 \mathrm{~mm}$ die diameter with steam addition compared to $7.9 \mathrm{~mm}$ die with or without steam addition.

\section{Cooling process}

Pellets leave the pellet press at temperatures of $60-95{ }^{\circ} \mathrm{C}$ and moisture contents of $12-18 \%$ (w.b.). Pellets are cooled using forced air immediately after the die to within $5{ }^{\circ} \mathrm{C}$ of ambient temperature. In general, the cooling time ranges from 4 to $15 \mathrm{~min}$. Pellets that are not properly cooled can have a reduced durability due to stresses in the pellet between the (cooled) outer layer and the (still) warmer center, which induces cracks in the pellets [28].

\section{Conclusions}

1. The main advantages of pelletizing biomass are: higher energy density, low transportation and storage costs and due to their size and composition, they can be easily used for feeding in domestic and industrial boilers.

2. Densification of biomass into pellets increases the bulk density, and so the calorific content is increased.

3. The quality of fuel pellets is assessed based on their density and durability; pellets with lower durability values break and increase the risk of storage issues.

\section{Acknowledgements}

This work was funded by the Executive Agency for Higher Education, Research, Development and Innovation Funding, within the project entitled "Optimizing the composition of biomass mixtures for obtaining high quality pellets”, ctr. 24 BG / 2016 (code PN-III-P2-2.1-BG-2016-0266), Romania.

\section{References}

[1] Department of Energy and Climate Change UK, [online] [19.03.2018] Available at: www.decc.gov.uk.

[2] Kaltschmitt M., Hartmann H. Energy from biomass-principles, techniques and methods. Berlin: Springer, 2009.

[3] Barmina I., Valdmanis R., Zake M., Ozola L., Strautins U. Development of gasification/combustion characteristics at thermochemical conversion of biomass mixtures. Proceedings of 16th International Scientific Conference Engineering for rural development, 2017, Jelgava, Latvia, pp. 54-59.

[4] Taylor R.E., Butzelaar P., Leeuwen G.V., Palmer A., Keyes J., Gimenez C., MacDonald B. Wood Pellet Market Outlook. In Wood Market International Monthly Report, vol. 18(1) 2013. Available at www. woodmarkets.com

[5] Peng J.H., Bi H.T., Lim C.J., Sokhansanj S. Study on density, hardness and moisture uptake of torrefied wood pellets. Energy Fuel, vol. 27, 2013, pp. 967-974.

[6] Lam P.S., Lam P.Y., Sokhansanj S., Bi X.T., Lim C.J. Mechanical and compositional characteristics of steam treated Douglas fir (Pseudotsuga menziesii L.) during pelletisation. Biomass Bioenergy, vol. 56, 2013, pp. 116-126.

[7] Stelte W. Fuel pellets from biomass: processing, bonding, raw materials - PhD Thesis, Technical University of Denmark, December 2011, ISSN 0106-2840, ISBN 978-87-550-3955-1. 
[8] ***Anyang Gemco Energy Machinery Co., Ltd., A guide to small scale pellet mill, [online] [19.03.2018] Available at: http://www.pelletmillequipment.com/document/TechnicalGuide-on-Wood-Biomass-Pellets-Production-final.pdf.

[9] Alakangas E., New European pellets standards. EUBIONET 3, 2011 [online] [19.03.2018] Available at: http://www.foex.fi/uploads/bioenergy/New_European_pellets_standards_March_2011.pdf.

[10] Tumuluru J.S., Conner C.C., Hoover A.N. Method to produce durable pellets at lower energy consumption using high moisture corn stover and a corn starch binder in a flat die pellet mill. Journal of Visualized Experiments, 2016, pp. 1-13.

[11] Adapa P., Tabil L., Schoenau G. A comprehensive analysis of the factors affecting densification of barley, canola, oat and wheat straw grinds. The Canadian Society for Bioengineering, No. CSBE 11-513, CSBE/SCGAB 2011 Annual Conference Inn at the Forks, Winnipeg, Manitoba, 2011.

[12] Kofman P.D. Preview of European standards for solid biofuels. Processing / Products No. 23, Coford Connects, Dublin, Ireland, 2010.

[13] Garcia-Maraver A., Perez-Jimenez J.A. Biomass pelletization - standards and production. UK: WIT Press, 2015. 194 p.

[14] Whittaker C., Shield I., Factors affecting wood, energy grass and straw pellet durability - a review. Renewable and Sustainable Energy Reviews, vol. 71, 2017, pp. 1-11.

[15] Gageanu I., Voicu Gh., Bunduchi G., Bracacescu C. Experimental research on the process of pelleting Salix Viminalis depending on humidity and granulation. Proceedings of 15th International Scientific Conference Engineering for rural development, May 25-27, 2016, Jelgava, Latvia, pp. 624-628.

[16] Miranda T., Montero I., Sepúlveda F.J., Arranz J. A., Rojas C.V., Nogales S. A review of pellets from different sources. Materials, vol. 8, 2015, pp. 1413-1427.

[17] Wilson O.T. Factors affecting wood pellet durability. Master Thesis, The Pennsylvania State University, 2010. 78 p.

[18] Adapa P., Tabil L., Schoenau G., Opoku A. Pelleting characteristics of selected biomass with and without steam explosion pretreatment. International Journal of Agricultural and Biological Engineering, vol. 3. 2010, pp. 62-79.

[19] Harun N.Y., Afzal M.T. Effect of particle size on mechanical properties of pellets made from biomass blends. Procedia Engineering, vol. 148, 2016, pp. 93-99.

[20] Stelte W., Clemons C., Holm J.K., Ahrenfeldt J., Henriksen U.B., Sanadi A.R., Fuel pellets from wheat straw: the effect of lignin glass transition and surface waxes on pelletizing properties. Boenergy Research, vol. 5, 2012, pp. 450-458.

[21] Jindaporn J., Charoenporn L. Influences of mixing ratios and binder types on properties of biomass pellets. Energy Procedia, vol. 138, 2017, pp. 1147-1152.

[22] Tarasov D., Shahi C., Leitch M. Effect of additives on wood pellet physical and thermal characteristics: a review. ISRN Forestry, Hindawi Publishing Corporation, Article ID 876939, 2013, pp. 1-6.

[23] European Pellet Council, Handbook for the certification of wood pellets for heating purposes. Version 2.0. April 2013, Brussels, Belgium. [online] [19.03.2018] Available at: http://www.enplus-pellets.eu/wp-content/uploads/2012/01/ENplus-Handbook-2.0.pdf.

[24] Stahl M., Berghel J., Granstrom K. Improvement of wood fuel pellet quality using sustainable sugar additives. BioResources, vol. 11, 2016, pp. 3373-3383.

[25] Tumuluru J.S., Wright C.T., Hess J.R., Kenney K.L. A review of biomass densification systems to develop uniform feedstock commodities for bioenergy application. Biofuels, Bioproducts and Biorefining, vol. 5, 2011, pp. 683-707.

[26] Tumuluru J.S. Effect of process variables on the density and durability of the pellets made from high moisture corn stover. Biosystems Engineering, vol.119, 2014, pp. 44-57.

[27] Tumuluru J.S., Tabil L., Opoku A., Mosqueda M.R., Fadeyi O. Effect of process variables on the quality characteristics of pelleted wheat distiller's dried grains with solubles. Biosystems Engineering, vol.105, 2010, pp. 466-475.

[28] Kaiyan N., Morey R.V. Factors affecting strength and durability of densified biomass products. Biomass and Bioenergy, vol. 33, 2009, pp. 337-359. 